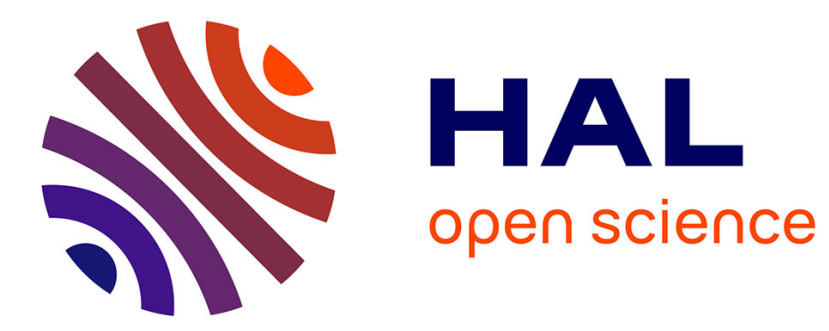

\title{
Ultra-compact $\mathrm{Ku}$ band rectenna
}

\author{
Alexandru Takacs, Hervé Aubert, Samuel Charlot
}

\section{To cite this version:}

Alexandru Takacs, Hervé Aubert, Samuel Charlot. Ultra-compact Ku band rectenna. International Microwave Symposium (IMS), May 2015, Phoenix, United States. 10.1109/MWSYM.2015.7166996 . hal-01237948

\section{HAL Id: hal-01237948 \\ https://hal.science/hal-01237948}

Submitted on 4 Dec 2015

HAL is a multi-disciplinary open access archive for the deposit and dissemination of scientific research documents, whether they are published or not. The documents may come from teaching and research institutions in France or abroad, or from public or private research centers.
L'archive ouverte pluridisciplinaire HAL, est destinée au dépôt et à la diffusion de documents scientifiques de niveau recherche, publiés ou non, émanant des établissements d'enseignement et de recherche français ou étrangers, des laboratoires publics ou privés. 


\title{
Ultra-Compact Ku band Rectenna
}

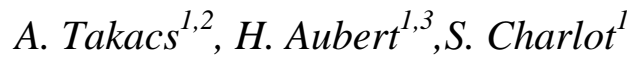 \\ ${ }^{1}$ CNRS, LAAS, 7 avenue du colonel Roche, F-31400 Toulouse, France \\ ${ }^{2}$ Univ. de Toulouse, UPS, LAAS, F-31400, Toulouse, France \\ ${ }^{3}$ Univ. de Toulouse, INP, LAAS, F-31400, Toulouse, France
}

\begin{abstract}
This paper addresses an innovative and ultracompact rectenna designed for energy harvesting or wireless power transfer applications. The presented rectenna uses a printed cross dipoles antenna array and a rectifier implemented with only one silicon Schottky diode. Experimental results show that $1.15 \mathrm{~mW}$ of DC power can be obtained for an optimal load impedance of $500 \Omega$ using a compact rectenna $\left(2.5 \mathrm{~cm}^{2}\right.$ or 0.6 square wavelength) illuminated by an electric field of $60 \mathrm{~V} / \mathrm{m}$ at 14.7 GHz.

Index Terms - Rectennas, microwave energy harvesting, wireless power transfer
\end{abstract}

\section{INTRODUCTION}

Microwave spectrum (beyond $10 \mathrm{GHz}$ ) presents an increased interest for wireless power transfer [1] or energy harvesting [2] applications. Rectenna topologies working at such frequencies were designed in the past [2]-[7] by using exclusively GaAs Schottky diodes. One of the main challenges of rectenna design, especially at such high frequencies, is to provide a high-efficiency by using a compact design and low-cost electronic components (e.g., silicon Schottky diodes). This paper addresses an innovative rectenna topology and the associated design methodology. The topology and the associated design rules are presented in Section II. The experimental results reported in Section III demonstrate that this topology allows implementing an ultracompact and high efficiency microwave rectenna.

\section{RECTENNA TOPOLOGY AND DESIGN}

The proposed topology selected to meet the two main design goals (i.e., conversion efficiency and structure compactness) is shown in Fig. 1. It is composed by: (i) a compact antenna array of two crossed printed dipoles located on the top of the PCB; (ii) a rectifier using only one Schottky diode. The rectifier (except the Schottky diode) is located at the bottom side of the PCB. A ground plane can be positioned below antenna/rectenna to immunize the rectenna performances from the electromagnetic properties of any mechanical support, to increase the gain of the antenna and consequently, to enhance the overall efficiency of the rectenna.

\section{A. Antenna design}

Three criteria were taken into account during antenna design and optimization: (i) compactness: the total size occupied by the antenna should be as small as possible, (ii) high gain/high efficiency: for maximizing the amount of the RF power available at the input of the rectifier and, (iii) input impedance matching: antenna input impedance $\left(Z_{\text {inA }}\right)$ has to match the input impedance of the rectifier $\left(Z_{\text {inR }}\right)$ for maximizing the power transfer between antenna and rectifier $\left(Z_{i n A}=Z_{i n R}{ }^{*}\right.$, where $Z_{i n R}{ }^{*}$ denotes the complex conjugate of $Z_{\text {inR }}$ ) at the targeted operating frequency.

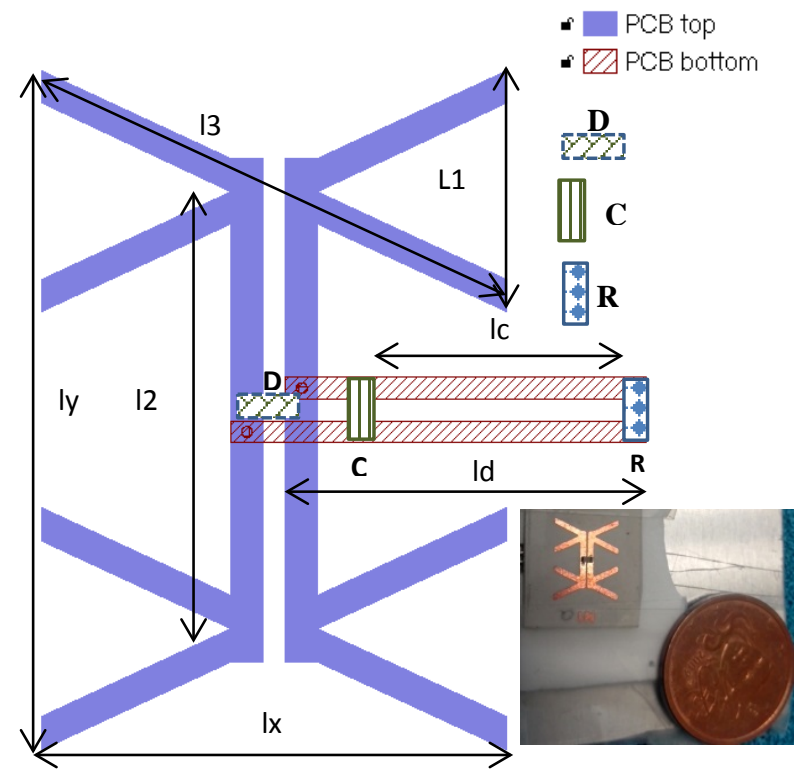

Fig. 1. Top view (not to scale) of the layout of the rectenna, its main geometrical dimensions and a photo (inset, right corner) of the manufactured rectenna

\section{B. Rectifier design}

A low-cost silicon Schottky diode (SMS201 from Aeroflex Metelics) in a molded plastic (DFN) package was adopted for this design. This diode can be used for broadband zero bias detectors or power detection up to $10 \mathrm{dBm}$ (frequency below $26.5 \mathrm{GHz}$ ). The SMS201 diode has a good thermal behavior and can be mounted using a classical soldering process at high temperature $\left(260^{\circ} \mathrm{C}\right)$ while the GaAs diodes require a more sensitive mounting process at a lower temperature $(<$ $150^{\circ} \mathrm{C}$ ). A RF shunt capacitor is connected between the diode and the load resistor as shown in Fig. 1. The simulation model of the rectifier was implemented into AWR software (Fig. 2). The diode was modeled based on the Metelics application note [8]. The rectenna was designed and fabricated on Rogers 6002 
substrate (relative permittivity: 2.94, loss tangent: 0.0012 and thickness: $508 \mu \mathrm{m})$.

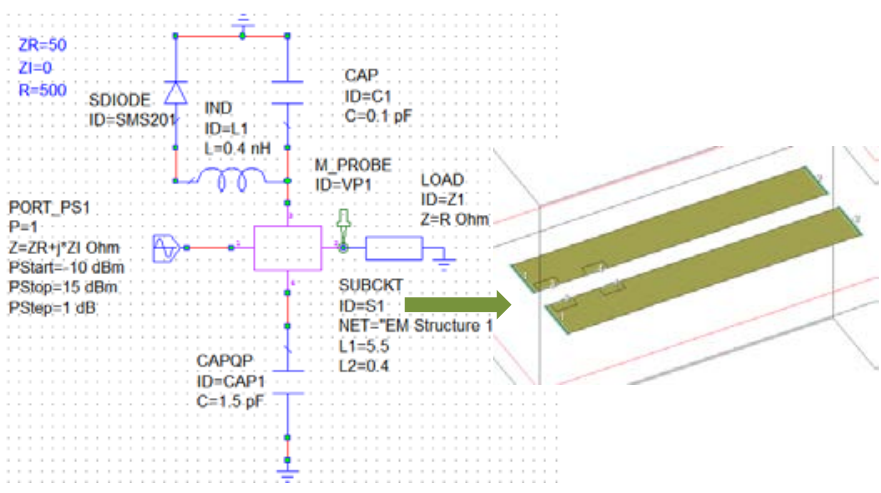

Fig. 2. Simulation model (AWR) of the rectifier.

\section{Design methodology and optimization process}

Rectenna design, simulation and optimization at such a high frequency involve the use of full-wave electromagnetic simulation tools combined with non-linear (e.g. harmonic balance) electrical circuit models.

First, non-linear simulations were performed by using the AWR model reported on Fig. 2 and an optimal value was determined for the shunt RF capacitor $(\mathrm{C}=1.5 \mathrm{pF})$ and for the load resistance $(\mathrm{R}=500 \Omega)$. The coplanar stripline sections supporting the rectifier were modeled as a sub-circuit at the electromagnetic level due to the lack of appropriate transmission line models in AWR. The via-hole used to connect the diode (mounted on the top side of the PCB) with the bottom of the PCB (the rectifier, except the diode, is located on the bottom side of the PCB) was not simulated in our model. A parametric analysis was performed in order to find the best position for the capacitor mounting. At this stage of the simulation it was found that the distance between the diode and the capacitor (ld-lc) should be as small as possible.

Second, a simulation model of the antenna array (top side of the PCB) was performed using Feko electromagnetic software. The main geometrical parameters of antennas are: the length of the crossed dipole arms (ld), the angle between crossed dipoles $(\alpha)$, the array step (12), the strip width (w) and, the gap between the strips of the coplanar stripline (g). The length of the crossed dipole arms (ld) and the array step (12) must be close to the half-wavelength at the operating frequency. In order to increase the gain of the antenna array and to immunize the rectenna performances from the electromagnetic properties of any mechanical support a metallic ground plane was positioned bellow the PCB. At this step of the design the radiation pattern and the current distribution on the strip section of antenna array were checked to verify the proper radiation mechanism. The input of antenna array is loaded by the rectifier impedance.

The rectenna layout is very compact and the antenna performances can be impacted by the presence of the rectifier. Thus an improved simulation model was developed by taking into account the entire layout (top and bottom side of the PCB). The diode was replaced by a voltage port while the capacitance $(1.5 \mathrm{pF})$ and the load impedance $(500 \Omega)$ were modeled as port loads. By using this simulation model the impact on antenna performances of the overall rectifier layout (except the non-linear behavior of the diode) was taken into account.

Finally the antenna layout (13 and 12) as well as the position of the shunt RF capacitor were tuned in order to ensure the matching condition $Z_{\text {inA }}=Z_{\text {inR }}{ }^{*}$.

\section{RESULTS}

The layout of the optimized rectenna was accommodated with the manufacturing tolerances available in a University unit equipped for general (low frequency) PCB manufacturing. A metallic plane was positioned at $1.2 \mathrm{~mm}$ below the rectenna with a $1.2 \mathrm{~mm}$ thick Rohacell (dielectric constant in the range of 1.08) intercalated as spacer between rectenna and its reflector. The main dimensions of the manufactured rectenna (see Fig. 1) are: $1 x=8.4 \mathrm{~mm}$, $l y=12.4 \mathrm{~mm}, \quad l 1=4.4 \mathrm{~mm}, \quad l 2=8 \mathrm{~mm}, \quad l d=6.5 \mathrm{~mm}, \quad l c=5.5 \mathrm{~mm}$ $13=10 \mathrm{~mm}, \mathrm{w}=0.6 \mathrm{~mm}$ and $\mathrm{g}=0.4 \mathrm{~mm}$. The overall surface of the PCB is $2.5 \mathrm{~cm}^{2}\left(0.6 \lambda^{2}\right)$.

\section{A. Experimental setup}

An experimental setup (shown in Fig. 3) was used in order to recreate the electromagnetic environment existing on antenna panels of the broadcasting satellites. A microwave signal generated from an Anritsu MG3694B generator was injected at the input of a horn antenna which illuminated the rectenna under test with a linear polarized E-field.

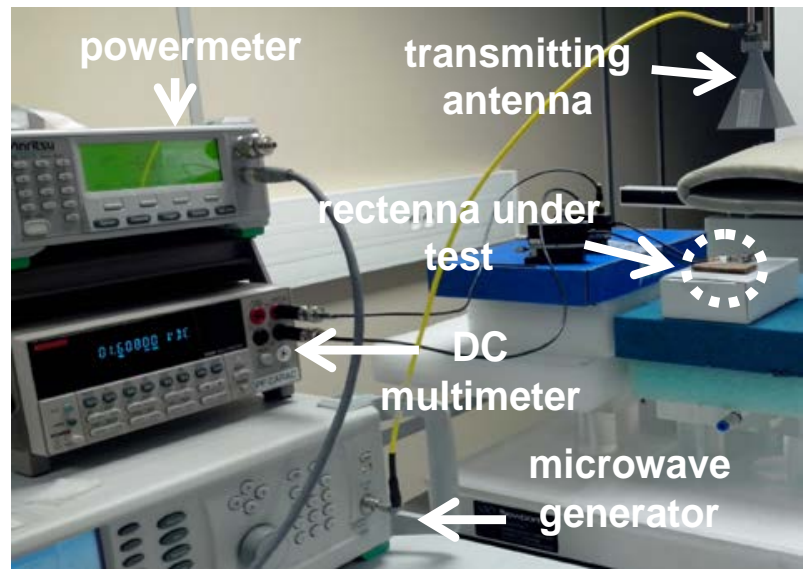

Fig. 3. Experimental setup.

An automatic acquisition routine was implemented in Labview software from National Instruments to speed-up the acquisition process. The harvested DC voltage was measured by using a DC multimeter. The DC power can be computed from the measured DC voltage as long as the load is known. The RF output power delivered by the signal generator was 24 $\mathrm{dBm}$ and the measured loss due to the coaxial cable and connectors between antenna and the signal generator was in the range of $2.5 \mathrm{~dB}$ in the operating frequency band. 


\section{B. Experimental and simulation results}

The simulated radiation pattern (gain) at $14.7 \mathrm{GHz}$ is shown in Fig. 4. A standard 3D Cartesian coordinate system with the vertical $\mathrm{Oz}$ axis perpendicular to the rectenna/antenna surface is chosen here.

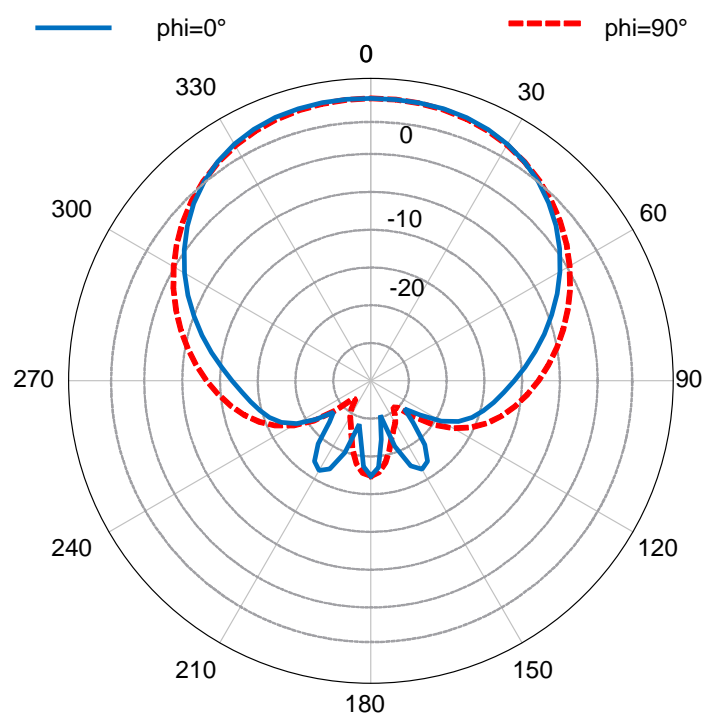

Fig. 4. Simulated (FEKO) gain of the antenna array: (xoz-plane: phi $=0^{\circ}$ and yoz-plane: $p h i=90^{\circ}$ ) at the frequency $\mathrm{f}=14.7 \mathrm{GHz}$.

The DC voltage on the input of a variable load (from $0.1 \mathrm{k} \Omega$ to $10 \mathrm{k} \Omega$ ) was measured for the fabricated rectenna. Fig. 5 shows the DC power measured with a load impedance of $500 \Omega$. The rectenna delivers the maximum power of $1.15 \mathrm{~mW}$ (load: $500 \Omega$ ) at $14.7 \mathrm{GHz}$. Fig. 6 shows the measured harvested DC power as function of the load impedance.

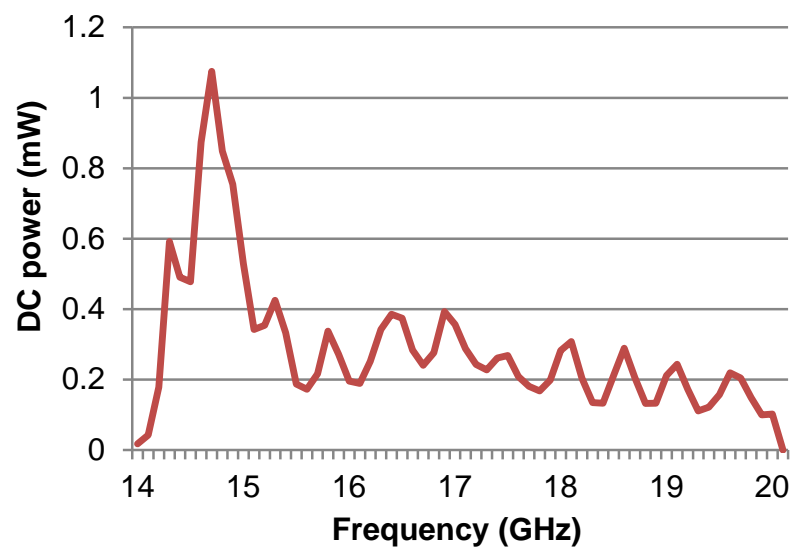

Fig. 5. Measured DC power on a load of $500 \Omega$ as function of frequency.

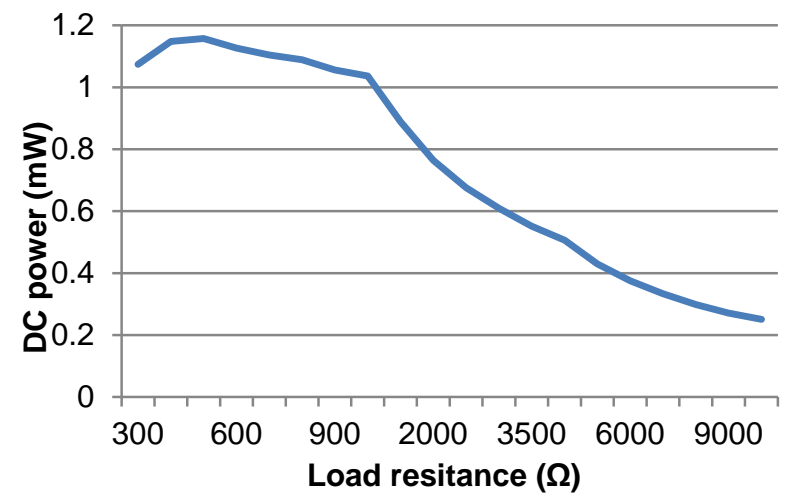

Fig. 6. Measured DC power at $14.7 \mathrm{GHz}$ as function of the load resistance.

The efficiency $\eta$ (in \%) of the rectenna can be computed by using the following definition [9]:

$$
\begin{aligned}
& \eta_{1}=\frac{P_{D C}}{S \cdot A_{G}} \cdot 100 \\
& \eta_{2}=\frac{P_{D C}}{S \cdot A_{\text {eff }}} \cdot 100=\frac{4 \cdot \pi \cdot P_{D C}}{S \cdot G_{R} \cdot \lambda^{2}} \cdot 100
\end{aligned}
$$

where $\mathrm{P}_{\mathrm{DC}}$ is the harvested $\mathrm{DC}$ power, $\mathrm{S}$ is the incident electromagnetic power density, $A_{G}$ (in $\mathrm{cm}^{2}$ ) denotes the area of the radiating surface, $A_{\text {eff }}$ is the antenna effective area, $G_{R}$ is the gain of the (rectenna's) antenna and $\lambda$ is the wavelength of the illuminating electromagnetic wave. The efficiency $\eta_{1}$ can be viewed as a 'worst-case' definition because $A_{\text {eff }} \leq A_{G}$ for any passive antenna. The power density $\left(\mu \mathrm{W} / \mathrm{cm}^{2}\right)$ can be computed as a function of E-field effective value $\mathrm{E}(\mathrm{V} / \mathrm{m})$ on the antenna surface or as a function of the RF power $\mathrm{P}_{t}$ delivered to the transmitting horn antenna of gain $G_{t}$ and positioned at the distance $d$ from the rectenna, as follows:

$$
S=\frac{E^{2}}{120 \cdot \pi} \cdot 100=\frac{30 \cdot P_{t} \cdot G_{t}}{d^{2} \cdot 120 \cdot \pi} \cdot 100
$$

Here $\mathrm{P}_{\mathrm{t}} \approx 21.5 \mathrm{dBm}, \mathrm{G}_{\mathrm{t}} \approx 16.9 \mathrm{dBi}$ and $\mathrm{d}=19 \mathrm{~cm}$. Thus $\mathrm{E} \approx 60$ $\mathrm{V} / \mathrm{m}$ and $\mathrm{S} \sim 955 \mu \mathrm{W} / \mathrm{cm}^{2}$. By taken into account the overall area of the rectenna $A_{G} \approx 2.5 \mathrm{~cm}^{2}$ a conversion efficiency around of $\eta_{1}=48 \% \quad\left(\eta_{2}=66 \%\right.$ by taking into account the simulated gain of $\mathrm{G}_{\mathrm{R}}=7.4 \mathrm{dBi}$ depicted in Fig. 4) at $14.7 \mathrm{GHz}$ (DC power of $1.15 \mathrm{~mW}$ ) were obtained. A comparison with the state-of-the-art (operating frequency beyond $10 \mathrm{GHz}$ ) is presented in Table I (note that all the diodes -except SMS201are GaAs diode). Few papers present the measured efficiency of the overall rectenna and, most papers report only the efficiency of the rectifier block of the rectenna. 
TABLE I

COMPARISON WITH PUBLISHED RECTENNAS (BEYOND OF $10 \mathrm{GHz}$ ).

\begin{tabular}{|c|c|c|c|c|}
\hline $\begin{array}{c}\mathbf{f} \\
(\mathrm{GHz})\end{array}$ & $\begin{array}{c}\eta \\
(\%)\end{array}$ & $\begin{array}{c}\text { Diode } \\
\text { Reference }\end{array}$ & $\begin{array}{c}\text { Size } \\
\left(\mathrm{mm}^{2}\right)\end{array}$ & Reference \& Comment \\
\hline 35 & 35 & $\begin{array}{c}\text { M/A Com } \\
\text { MA4E- } \\
1317\end{array}$ & $>110$ & $\begin{array}{l}\text { [4]: efficiency (received RF } \\
\text { power/output DC power) measured } \\
\text { using a free space setup for } \mathrm{S}=30 \\
\mathrm{~mW} / \mathrm{cm}^{2} \text { and a load of } 50 \Omega\end{array}$ \\
\hline 24 & 54.6 & $\begin{array}{l}\text { M/A Com } \\
\text { MADS- } \\
\text { 001317- } \\
\text { 1320AG }\end{array}$ & $\mathrm{NR}^{*}$ & $\begin{array}{l}\text { [5]: efficiency (received RF } \\
\text { power/output DC power) measured } \\
\text { using a near field setup for } 130 \mathrm{~mW} \\
\text { of RF input power at the input of the } \\
\text { rectifier and a load of } 400 \Omega\end{array}$ \\
\hline 25.7 & 17 & $\begin{array}{l}\text { M/A Com } \\
\text { MA4E- } \\
\text { 2502L }\end{array}$ & 328.5 & $\begin{array}{l}\text { [7]: only the efficiency of the } \\
\text { rectifier part is reported; value } \\
\text { obtained for a RF power of } 8 \mathrm{dBm} \text { at } \\
\text { the diode input and a load of } 1500 \Omega\end{array}$ \\
\hline 18.8 & 42 & $\begin{array}{l}\text { MZBD- } \\
9161\end{array}$ & 280 & $\begin{array}{l}\text { [2]: E-field of } 91 \quad \mathrm{~V} / \mathrm{m} \quad(\mathrm{S}=2.2 \\
\left.\mathrm{mW} / \mathrm{cm}^{2}\right) \text { for a load of } 510 \Omega\end{array}$ \\
\hline 24 & 24 & $\begin{array}{c}\text { M/A Com } \\
\text { MA4E- } \\
1317 \\
\end{array}$ & $>1800$ & $\begin{array}{l}{[6]: \mathrm{S}=10 \mathrm{~mW} / \mathrm{cm}^{2} \text {; use of a circular }} \\
\text { polarized antenna array }\end{array}$ \\
\hline 14.7 & $\begin{array}{c}48 \\
(66)\end{array}$ & SMS201 & 250 & $\begin{array}{l}\text { This paper: } E=60 \mathrm{~V} / \mathrm{m} ; \mathrm{S}=0.95 \\
\mathrm{~mW} / \mathrm{cm}^{2} \text { for a load of } 500 \Omega \text {. }\end{array}$ \\
\hline 23.15 & 25 & SMS201 & 250 & $\begin{array}{l}\text { [10]: } E=73 \mathrm{~V} / \mathrm{m}\left(\mathrm{S}=1.4 \mathrm{~mW} / \mathrm{cm}^{2}\right) \text { for } \\
\text { a load impedance of } 300 \Omega\end{array}$ \\
\hline
\end{tabular}

\section{CONCLUSION}

A compact rectenna $\left(0.6 \lambda^{2}\right)$ operating in Ku-band was designed and characterized. Despite of the use of a low-cost silicon Schottky diode the manufactured rectenna exhibits an efficiency of $48 \%$ at $14.7 \mathrm{GHz}$. This rectenna exhibits an excellent trade-off between compactness and efficiency.

\section{ACKNOWLEDGMENT}

This work was partially supported by CNES French Space Agency within the framework of R\&T $n^{\circ} 115052$ contracts. The electronic laboratory of University of Toulouse (Paul Sabatier) is acknowledged for PCB manufacturing.

\section{REFERENCES}

[1] B. Strassner, K. Chang, "Microwave Power Transmission: Historical Milestones and system Components", Proceedings of the IEEE, Vol. 101, No. 6, pp.1379 -1395, June 2013.

[2] A. Takacs, H. Aubert, S. Fredon, L. Despoisse, H. Blondeaux, "Microwave power harvesting for satellite health monitoring," IEEE Trans. on Microwave Theory Tech, Vol.: 62, Issue: 4 , pp. 1090 - 1098, April 2014.

[3] T.-W. Yoo and K. Chang, "Theoretical and experimental development of 10 and $35 \mathrm{GHz}$ rectennas," IEEE Trans. Microw. Theory Techn., vol.40, no. 6, pp. 1259-1266, Jun. 1992.

[4] Y.-J. Ren, M.-Y. Li, K. Chang, "35 GHz rectifying antenna for wireless power transmission," IET Electronics Letters, vol.43, no.11, pp.602-603, May 242007.

[5] N. Shinohara, K. Nishikawa, T. Seki, K.Hiraga, "Development of 24 $\mathrm{GHz}$ rectennas for Fixed Wireless Access," 2011 URSI General Assembly and Scientific Symp., pp.1-4, 13-20 Aug. 2011.

[6] S. Ladan, A.B. Guntupalli, K. Wu, "A High-Efficiency $24 \mathrm{GHz}$ Rectenna Development Towards Millimeter-Wave Energy Harvesting and Wireless Power Transmission”, IEEE Trans. Circuits and Systems I: Regular Papers, vol. 61, no. 12, pp. 3358-3366, Dec. 2014.
[7] A. Collado, A. Georgiadis, "24 GHz Substrate Integrated Waveguide (SIW) Rectenna for Energy Harvesting and Wireless Power Transmission, in Proc. of IMS'2013, 2013.

[8] http://www.aeroflex.com/AMS/Metelics/pdfiles/SMS201.pdf

[9] Z. Popovic; E.A. Falkenstein, D. Costinett, R. Zane, "Low-Power FarField Wireless Powering for Wireless Sensors", Proceedings of the IEEE, Vol. 101, No. 6, pp.1397 -1407, June 2013.

[10] A. Takacs, H. Aubert, A. Luca, S. Charlot, S. Fredon, L. Despoisse, "Rectenna Design for K Band Application", 2014 European Microwave Conference (EUMC'2014), Rome, Italy, 5-10 Oct'2014. 